\title{
Geociênçiasias
}

\section{Uso de dados SRTM e plataforma SIG na caracterização morfométrica da bacia hidrográfica do Braço Norte do Rio São Mateus - Brasil}

\author{
Use of SRTM data and GIS platform in the \\ morphometric characterization of the watershed \\ of the North tributary of São Mateus River - Brazil
}

\author{
Abrahão Alexandre Alden Elesbon \\ Msc., Professor IFES/Colatina, \\ Doutorando em Recursos Hídricos \\ e Ambientais (DEA/UFV). \\ abrahaoelesbon@hotmail.com
}

Hugo Alexandre Soares Guedes

Msc., Engenheiro Civil, Doutorando

em Recursos Hídricos e Ambientais

(DEA/UFV).

hugo.guedes@ufv.br

\section{Demetrius David da Silva \\ Dr., Professor Associado do \\ Departamento de Engenharia \\ Agrícola da UFV. \\ demetrius@ufv.br}

lara de Castro e Oliveira

Graduanda em Engenharia

Ambiental da UFV. Bolsista

de IC (DEA/UFV).

iaracasoli@yahoo.com.br

\section{Resumo}

A delimitação de uma bacia hidrográfica e sua caracterização morfométrica são procedimentos comumente utilizados em análises hidrológicas e ambientais. $\mathrm{O}$ advento e a consolidação dos Sistemas de Informações Geográficas (SIG’s) e o aprimoramento na geração dos Modelos Digitais de Elevação (MDE's) têm contribuído, de forma expressiva, no desenvolvimento de metodologias automáticas para obtenção de variáveis morfométricas de forma mais eficiente, confiável e com reprodutibilidade científica. Nesse trabalho, objetivou-se a geração do Modelo Digital de Elevação Hidrograficamente Condicionado (MDEHC) para a bacia hidrográfica do Braço Norte do rio São Mateus, a partir dos dados remotos da missão SRTM, visando a obter as características fisiográficas da referida bacia. Gerado o MDEHC para a região estudada, foram obtidas as seguintes características morfométricas: área de drenagem, perímetro, forma da bacia (Kc, Kf), hierarquização dos cursos d'água, densidade de drenagem, densidade de confluências, declividade média da bacia, altitude média da bacia e declividades do curso de água principal. Após a análise dos resultados obtidos, concluiu-se que as operações espaciais de vizinhança e conectividade, implementadas em ambiente matricial, apresentaram ótimos resultados na obtenção das características físicas da bacia, de forma rápida, confiável e com reprodutibilidade científica garantida.

Palavras-chave: MDEHC, Caracterização morfométrica, rio São Mateus e SRTM.

\begin{abstract}
The delineation of a watershed and it's morphometric characterization procedures are commonly used in environmental and hydrological analysis. The advent and consolidation of Geographic Information Systems (GIS) and the improvement in the generation of Digital Elevation Models (DEM's) have contributed significantly to the development of automatic methodologies to obtain explanatory variables in a more efficient and reliable manner, ensuring scientific reproducibility. The objective of this study was to generate a Conditioning Hydrographic Digital Elevation Model (CHDEM) for the basin of the northern tributary of the São Mateus River, from the SRTM remote data. Generated the CHDEM for the studied area, we obtained the following morphometric characteristics: drainage area, perimeter, shape of the basin
\end{abstract}


$(K c, K f)$, prioritization of water courses, drainage density, density of intersections, an average slope for the basin, average elevation of the basin and slope of the main water course. Space operations of neighborhood and connectivity, implemented in a matrix environment, showed excellent results in obtaining the physical characteristics in a fast, reliable manner and with guaranteed scientific reproducibility.

Keywords: CHDEM, Morphometric characterization, São Mateus River and SRTM.

\section{Introdução}

Uma bacia hidrográfica pode ser entendida como uma área definida topograficamente, drenada por um curso de água ou um sistema conectado de cursos de água, tal que toda vazão efluente seja descarregada por uma única saída (Tucci, 2004). Os principais componentes solo, água, vegetação e fauna - coexistem em permanente e dinâmica interação, respondendo às interferências naturais e àquelas de natureza antrópica, afetando os ecossistemas como um todo. Nesses compartimentos naturais - bacia hidrográfica -, os recursos hídricos constituem indicadores das condições dos ecossistemas, no que tange aos efeitos do desequilíbrio das interações dos respectivos componentes (Souza et al., 2002).

Desse modo, as características físicas e bióticas de uma bacia possuem importante papel nos processos do ciclo hidrológico, influenciando, sobretudo, a infiltração, a quantidade de água produzida como deflúvio, a evapotranspiração e o escoamento superficial e subsuperficial específicos para determinado local, de forma a qualificarem as alterações ambientais (Alves \& Castro, 2003).

A delimitação de uma bacia hidrográfica é um dos primeiros e mais comuns procedimentos executados em análises hidrológicas ou ambientais. Para isso, tem sido comum a utilização de informações de relevo em formato analógico, como os mapas e cartas, o que compromete a confiabilidade e a reprodução dos resultados devido à carga de subjetividade inerente aos métodos manuais (Cardoso et al., 2006). Com o advento e a consolidação dos Sistemas de Informações Geográficas (SIG’s) e, conseqüente-

\section{Materiais e métodos}

\section{Área de estudo}

A região em estudo situa-se a montante da estação fluviométrica São João da Cachoeira Grande (código 55850000), pertencente à rede da Agência Nacional de Águas - ANA e operada pela Compa- mente, o surgimento de formas digitais consistentes de representação do relevo, como os Modelos Digitais de Elevação (MDE's), métodos automatizados têm sido desenvolvidos até então (Garbrecht \& Martz, 1999).

Os SIG's têm sido muito utilizados devido à sua flexibilidade e disponibilidade, consistindo de sistemas compudiversas informações espaciais da bacia hidrográfica. A informação é armazenada digitalmente e apresentada visual ou graficamente, permitindo a comparação e a correlação entre informações. A utilização dos SIG's para o gerenciamento ambiental de bacias hidrográficas envolve muitas outras atividades, além da elaboração e manutenção de um banco de dados geocodificados, de onde são retiradas as diversas informações estatísticas sobre as características da unidade de estudo (Pires et al., 2002).

De acordo com ESRI (2010), modelar digitalmente uma superfície, de modo consistente, significa representar o relevo de forma a reproduzir, com exatidão, o caminho preferencial do escoamento da água superficial observado no mundo real. A utilização de modelos digitais de elevação hidrograficamente condicionados (MDEHC), por intermédio do uso de sistema de informações geográficas, é fundamental para obtenção automática das características morfométricas das bacias de drenagem.

Os MDEHC's gerados a partir de informações de sensores remotos, tal como a missão Shuttle Radar Topography Mission (SRTM), realizada em 2000 a bordo da nave Endeavour, têm tadorizados, que permitem sobrepor nhia de Pesquisa de Recursos Minerais - CPRM.

A estação está localizada na região hidrográfica do Atlântico trecho Leste, braço norte do rio São Mateus, ganhado relevância por advirem de uma técnica rápida e acurada de coletar dados topográficos (Rabus et al., 2003). Assim, diversas pesquisas vêm sendo realizadas objetivando-se analisar, comparar e atualizar informações de superfície terrestre por meio de dados SRTM (Valeriano et al., 2006; Ludwig \& Schneider, 2006; Fredrick et al., 2007; Rennó et al., 2008; Alcaraz et al., 2009; Oliveira et al., 2010).

A extração das características morfométricas a partir de MDEHC's gerados por meio de dados orbitais tem recebido atenção considerável e é reconhecida como uma alternativa viável aos tratamentos tradicionais e à avaliação manual dos mapas topográficos, uma vez que as bacias reduzem o tempo necessário para a geração de planos de informações para modelos hidrológicos (Colombo et al., 2007). As vantagens da automação são a maior eficiência e confiabilidade dos processos, a reprodutibilidade dos resultados e a possibilidade de armazenamento e compartilhamento dos dados digitais. Neste sentido, a utilização de bases topográficas obtidas por sensores orbitais representa uma alternativa de grande interesse para suprir a necessidade de intervenções manuais na modelagem do relevo.

Diante do exposto, os objetivos do trabalho foram: determinar as características morfométricas comumente empregadas em análises hidrológicas e ambientais para a bacia do Braço Norte do rio São Mateus por meio de dados SRTM e plataforma SIG e comparar os resultados obtidos com trabalhos anteriores, desenvolvidos para a área em estudo, para validação dos procedimentos utilizados. nas coordenadas geográficas $18^{\circ} 33^{\prime}$ $50^{\prime \prime} \mathrm{S}$ e $40^{\circ} 20^{\prime} 10^{\prime \prime} \mathrm{W}$ e altitude $29 \mathrm{~m}$, delimitando uma área de drenagem a montante de aproximadamente 7.000 $\mathrm{km}^{2}$. 


\section{Obtenção do MDEHC}

O MDE utilizado no estudo foi obtido através das imagens SRTM - Shuttle Radar Topography Mission - disponibilizadas no site da EMBRAPA (Miranda, 2005), na resolução de 90 x 90 m, e com extensão espacial semelhante ao sistema de articulação cartográfico utilizado pelo Instituto Brasileiro de Geografia e Estatís-

Figura 1

Localização geográfica da bacia do rio São Mateus e do posto fluvio métrico (código 55850000) a partir do mosaico construído com dados

SRTM obtidos da EMBRAPA.

Inicialmente projetou-se toda a base de dados para WGS - 1984 - UTM - Zone - 24S, tomando-se o cuidado de transformar todas as células geradas para o tamanho inteiro de $90 \mathrm{~m}$ (aproximadamente 3 arcos-segundos). A área de trabalho, também, foi modificada, para que não houvesse problemas na continui-

Figura 2

Bacia hidrográfıca, drenagem numérica e localização da estação fluviométrica (código 55850000). tica - IBGE (Figura 2). Segundo Miranda (2005), essas imagens equivalem às cartas do IBGE na escala de 1:250.000. Foram selecionadas, previamente, as seguintes cartas: SE-24-V-C, SE-24-Y-A, SE-24-Y-B.

$O$ software utilizado para manipulação das imagens SRTM e obtenção do MDEHC foi o $\operatorname{ArcGIS}^{\circledR} 9.3$ do ESRI. Na
Figura 1, está apresentada a localização da bacia do rio São Mateus, a partir do mosaico das três imagens obtidas. Pode ser identificado, na figura, o braço norte e sul do rio São Mateus. Também pode ser identificada a posição geográfica da estação fluviométrica São João da Cachoeira Grande (55850000).

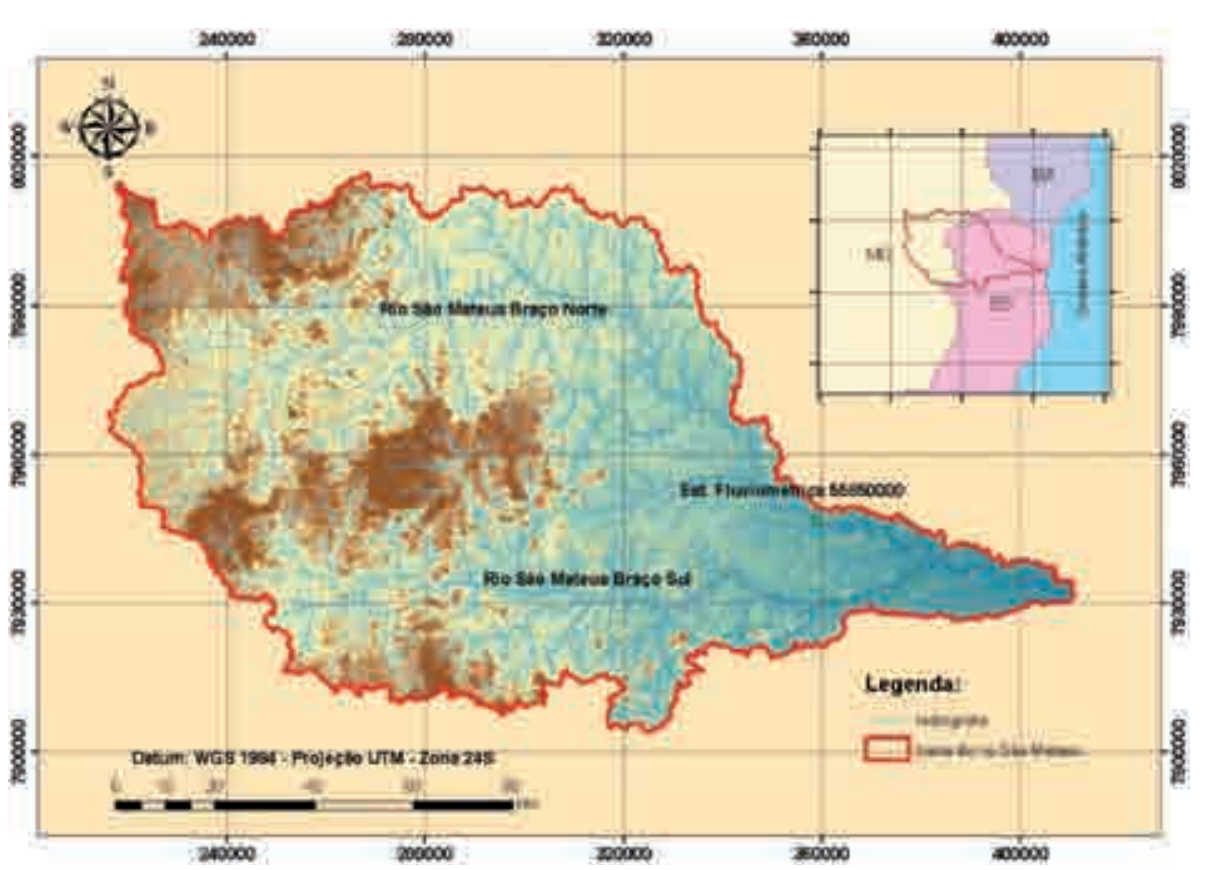

dade do trabalho.

Verificou-se uma inconsistência nos arquivos obtidos do site da EMBRAPA, encontrando-se muitas células com valores "no data”. Estas células não possuem nenhuma informação geográfica e não podem ser definidas como depressões espúrias (altitudes equivocadas devido ao processo de interpolação ou obtenção da imagem por satélite). Identificam-se as células com valores "no data", utilizando-se a ferramenta de análise espacial do software ArcGIS ${ }^{\circledR} 9.3$ “is null”. Após esse procedimento, substituíram-se as células sem informações geográficas por células com altitude estipulada de 1 metro.

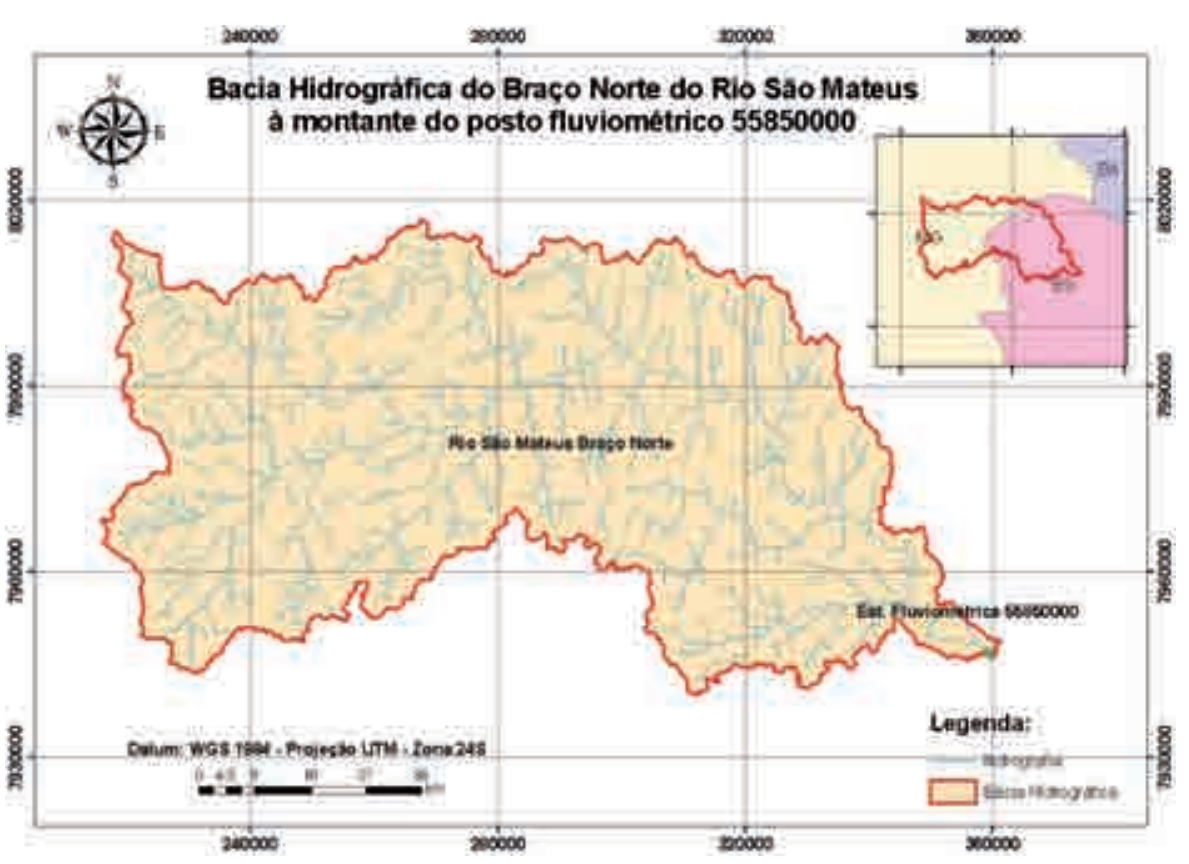


Após esse procedimento inicial, utilizou-se o conjunto de ferramentas do ArcGIS $^{\circledR}$ 9.3, denominado ArcHydro, utilizado para geração de banco de dados hidrológicos e análises espaciais de gestão de recursos hídricos. No processamento do terreno, a seqüência de comandos utilizados foi: preenchimento das depressões espúrias (inclusive das células acrescentadas com altitude $1 \mathrm{~m}$ nas regiões de "no data”), criação do grid de direção de escoamento, criação do grid de fluxo acumulado e criação da drenagem numérica com acúmulo inicial de 500 células.

De posse de todos esses grids, determinou-se a posição do posto fluviométrico sobre a drenagem numérica e criouse a célula correspondente à foz, sendo gerada a sua área de drenagem. A partir desta primeira delimitação da bacia, configuram-se todas as análises espaciais para essa região, aumentando a agilidade e reduzindo o tempo de processamento do software.

\section{Parâmetros morfométricos}

A caracterização morfométrica da bacia de drenagem foi feita a partir da avaliação de variáveis físicas do relevo e da rede de drenagem. Esses parâmetros vêm sendo utilizados por diversos pesquisadores para a compreensão de fenômenos naturais e antrópicos (Collares, 2000; Lana et al., 2001; Santos \& Sobreira, 2008; Lima Neto et al., 2008).

No presente trabalho, foram analisados os seguintes parâmetros: área de drenagem (A) e perímetro da bacia $(\mathrm{P})$, coeficiente de compacidade (Kc), fator de forma (Kf), hierarquização dos cursos d'água (Strahler, 1952), densidade de drenagem (Dd), densidade de confluências (Dc), declividade média da bacia, declividade do rio principal obtida por quatro diferentes metodologias (S1-declividade obtida com base na diferença de nível entre a nascente e a foz; S2- declividade obtida com base no critério de equivalência de áreas; S3-declividade equivalente constante obtida com base na velocidade de deslocamento da água ao longo do perfil longitudinal do curso d'água e S4declividade obtida considerando apenas o trecho intermediário do curso d'água correspondente a $75 \%$ do seu comprimento), comprimento do rio principal e comprimento total dos cursos de água. É importante ressaltar que todas essas características morfométricas foram obti-
Foi realizada, então, a comparação da hidrografia gerada com acúmulo de 500 e 100 células com a hidrografiapadrão do IBGE para a escala utilizada (1:250.000) numa região de cabeceira.

O próximo passo para a construção do MDEHC foi o afinamento da hidrografia. Esse procedimento se deve, principalmente, à suavização da rede de drenagem, visando às verificações topológicas e à orientação da hidrografia no sentido nascente-foz (Marques et al., 2009). A topologia foi realizada a partir da hidrografia afinada e vetorizada. Algumas regras topológicas são adicionadas ao tema para evitar incoerências na hidrografia. As regras selecionadas foram: não deve haver cursos de água com comprimentos inferiores a três células do grid (must not have dangles), o rio não pode intersectarse (must not self-intersect) e a hidrografia deve apresentar trechos contínuos (must not have pseudo-nodes).

Após a verificação topológica, procedeu-se a verificação do sentido de es-

coamento, garantindo-se o escoamento no sentido das nascentes para a foz. Esse procedimento é bastante interessante, pois detecta, apesar de todo procedimento de tratamento inicial do MDE, escoamentos incoerentes e inconsistentes.

Por fim, o último procedimento realizado para a construção do MDEHC foi garantir que a hidrografia passasse pela hidrografia refinada (hidrografia de pixels não paralelos e largura de apenas 1 pixel), orientada e topologicamente consistida. Para tanto, foram utilizados algoritmos específicos do software, onde se aprofunda o grid de elevação da hidrografia numérica para garantir a continuidade do escoamento até a foz. Com a hidrografia aprofundada no MDE, refaz-se todo o procedimento de preenchimento de depressões espúrias que porventura possam ter sido geradas, gerando, então, uma nova direção de escoamento e um novo fluxo acumulado. A partir de então podese considerar hidrograficamente condicionado o modelo digital de elevação.

das de forma automática, de acordo com a metodologia descrita por Marques et al. (2009), por meio do MDEHC gerado a partir das imagens SRTM.

A seguir são apresentadas, resumidamente, as contribuições de cada variável morfométrica analisada nesse estudo para análises hidrológicas e ambientais:

- Área de Drenagem e perímetro da bacia - fornecem subsídios para avaliação do nível de irregularidade que a forma da bacia apresenta.

- Coeficiente de compacidade e coeficiente de forma - Os coeficientes de compacidade e de forma são úteis para indicar a susceptibilidade da bacia à ocorrência de enchentes. Uma bacia hidrografia será tanto mais suscetível à enchentes quanto mais próximo da unidade for o coeficiente de compacidade e quanto menor o valor do coeficiente de forma.

- Hierarquização dos cursos d'água $\left(n^{\circ}\right.$ ordem) - Reflete o grau de ramificação ou bifurcação da rede de drenagem da bacia, indicando a maior ou menor velocidade com que a água deixa a bacia hidrográfica, sendo fator indicativo de sua propensão à ocorrência de cheias.

- Densidade de Drenagem e densidade de confluências - Indicam a eficiência do sistema de drenagem. Quanto maior a densidade de drenagem ou a densidade de confluências de uma bacia maior a capacidade dos cursos d'águas que a constituem drenarem o escoamento superficial diminuindo a possibilidade de ocorrência de enchentes.

- Declividade média da bacia - Fator que influencia a velocidade de escoamento da água sobre o solo e interfere na capacidade de armazenamento de água neste. Quanto mais declivosas as bacias, menor capacidade de armazenamento superficial. Quanto maior a declividade de uma bacia, mais suscetível esta será à ocorrência de erosões (Pruski, 2006).

- Declividade do rio principal - A velocidade de escoamento de um rio depende da declividade dos canais fluviais, sendo que, quanto maior sua declividade, maior será a velocidade de escoamento.

- Comprimento do rio principal e comprimento total dos cursos d'água - Esses fatores estão diretamente relacionados com o tamanho da bacia e a eficiência do sistema de drenagem respectivamente.

Mais detalhes sobre a metodologia utilizada para determinação dos parâmetros morfométricos encontram-se na literatura especializada de Villela e Mattos (1975), Lima (1986) e em trabalhos técnicos de Lima Neto et al. (2008), Santos \& Sobreira (2008) e Marques et al. (2009). 
Figura 3

Comparação da hidrografia-padrão IBGE (vermelha), hidrografia numérica gerada para 500 células acumuladas (azul) e 100 células acumuladas (verde).

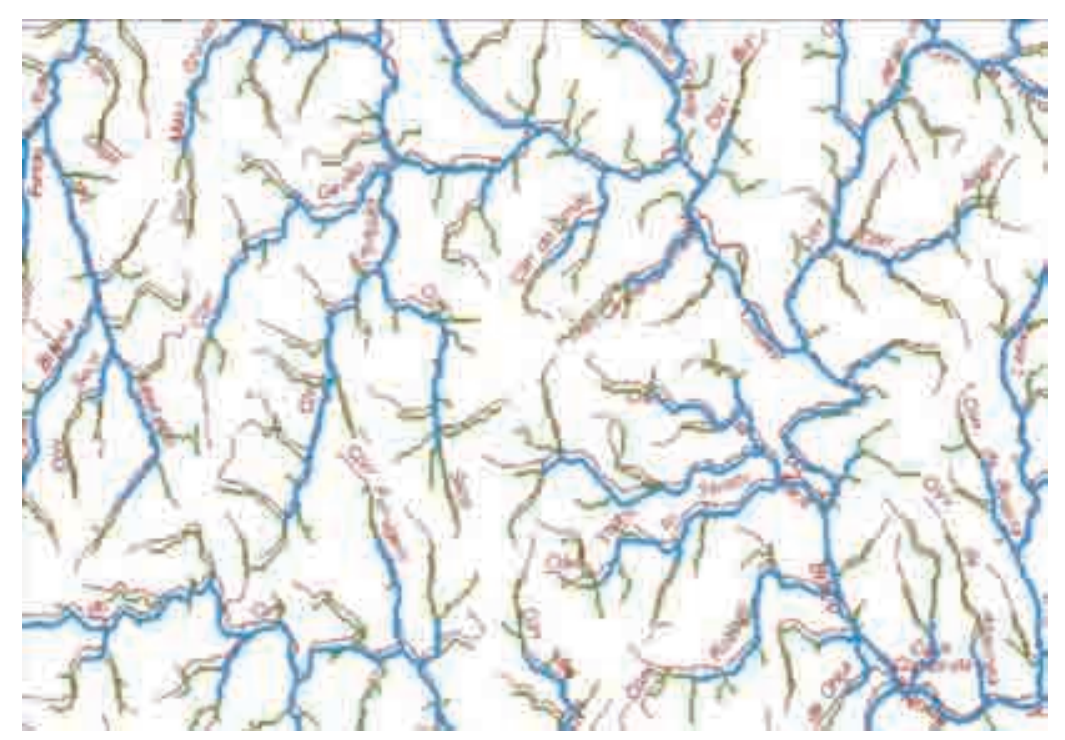

\section{Resultados e discussão}

\section{Obtenção do MDEHC}

Na Figura 2, está apresentada a delimitação da bacia hidrográfica a montante do posto fluviométrico São João da Cachoeira Grande (código 55850000), bem como a hidrografia gerada e vetorizada.

A verificação básica da consistência hidrológica do modelo digital de elevação baseou-se na comparação da hidrografia gerada com a disponibilizada pelo órgãopadrão cartográfico nacional (IBGE), Figura 3, e na delimitação precisa da bacia hidrográfica.

Observa-se, pela Figura 3, que a hidrografia numérica gerada é compatível com a rede de drenagem-padrão. $\mathrm{O}$

\section{Parâmetros morfométricas}

Na Tabela 1, está apresentada a síntese dos parâmetros morfométricos obtidos para a região em estudo.

Tabela 1

Síntese dos parâmetros morfométricos obtidos, para a bacia do rio São Mateus, à montante do posto de monitoramento fluviométrico 55850000 . nível de ramificação para 500 células é menor que aquele apresentado pelo IBGE e, para 100 células, é maior. Optou-se por manter a drenagem numérica gerada para 500 células por diminuir o tempo de processamento e por coincidir, de forma mais aceitável, com a drenagem-padrão.

A comparação gráfica com a carta do IBGE foi feita com intuito de sugerir um valor, criterioso, para hidrografia modelada (numérica) que tenha uma relação mais próxima com o valor fornecido pela base de dados oficial. Busca-se, na utilização do MDEHC, uma aproximação com a situação "real" para a escala em estudo ( 1:250.000). Portanto o valor ao qual se atribui o início da drenagem numérica é um valor complexo, que não tem sido adotado, de forma padronizada, pelos pesquisadores. A comparação dos resultados obtidos, referentes ao nível de ramificação e drenagem, só poderá ser feita caso se respeite esse critério ou se atualize a base de dados oficial visando a uma gestão de recursos hídricos mais condizente com a realidade.

Sugere-se que a base de dados oficial forneça, precisamente, a posição geográfica de todas as nascentes das bacias hidrográficas, para uma melhor definição no nível de ramificação das drenagens modeladas.
A área de drenagem obtida, nesse trabalho, foi de $6.928,74 \mathrm{~km}^{2}$ e o perímetro da bacia foi igual a $665 \mathrm{~km}$. Segundo
Ana (2010), a área de drenagem, para esse posto fluviométrico, é de $6.732 \mathrm{~km}^{2}$, utilizando uma base de dados na escala

\begin{tabular}{|c|c|c|c|c|}
\hline \multicolumn{3}{|c|}{ Parâmetros Morfométricos } & Unidade & Resultado \\
\hline \multirow{4}{*}{ Forma da bacia } & \multicolumn{2}{|l|}{ Área } & $\mathrm{km}^{2}$ & $6.928,74$ \\
\hline & \multicolumn{2}{|c|}{ Perímetro } & $\mathrm{km}$ & 665 \\
\hline & \multicolumn{2}{|c|}{ Coeficiente de compacidade } & - & 2,24 \\
\hline & \multicolumn{2}{|c|}{ Fator de forma } & - & 0,259 \\
\hline \multirow{5}{*}{$\begin{array}{l}\text { Sistema de } \\
\text { drenagem }\end{array}$} & \multicolumn{2}{|c|}{ Comprimento do rio principal } & $\mathrm{km}$ & 251,01 \\
\hline & \multicolumn{2}{|c|}{ Comprimento total da hidrografia } & $\mathrm{km}$ & $2.540,34$ \\
\hline & \multicolumn{2}{|c|}{ Densidade de drenagem } & $\mathrm{km} \mathrm{km}^{-2}$ & 0,367 \\
\hline & \multicolumn{2}{|c|}{ Densidade de confluências } & conf km-2 & 0,068 \\
\hline & \multicolumn{2}{|c|}{ Ordem do rio principal (Strahler) } & - & 5 \\
\hline \multirow{6}{*}{ Relevo da bacia } & \multicolumn{2}{|c|}{ Declividade média } & $\%$ & 21,24 \\
\hline & \multicolumn{2}{|l|}{ Elevação média } & $\mathrm{m}$ & 344,19 \\
\hline & \multirow{4}{*}{ Declividade do rio principal } & S1 & $\mathrm{m} \mathrm{m}^{-1}$ & 0,0028 \\
\hline & & S2 & $\mathrm{m} \mathrm{m}^{-1}$ & 0,0014 \\
\hline & & S3 & $\mathrm{m} \mathrm{m}^{-1}$ & 0,0011 \\
\hline & & S4 & $\mathrm{m} \mathrm{m}^{-1}$ & 0,0020 \\
\hline
\end{tabular}


do milionésimo. Elesbon (2004) obteve, para a estação em análise, valor para a área de drenagem igual a $7.537 \mathrm{~km}^{2}$, utilizando a escala ao milionésimo e o traçado da bacia hidrográfica de forma semi-automática (delineada pelo usuário a partir de imagens tridimensionais).

Segundo Vilella e Matos (1975), a tendência a enchentes é tanto mais acentuada quanto mais próximo da unidade for o valor do coeficiente de compacidade e quanto mais baixo for o coeficiente de forma. O Kc obtido para a bacia do rio São Mateus foi igual a 2,24, indicando que a mesma apresenta menor propensão para ocorrência de enchentes no que diz respeito à sua forma. A bacia apresenta Kf igual 0,259, também indicando menor propensão da mesma à ocorrência de enchentes, uma vez que, quanto maior o comprimento axial em relação à área, menores são as chances de ocorrência de enchentes numa bacia.

O comprimento do rio principal e, comprimento total dos cursos de água apresentaram, respectivamente, os valores $251,01 \mathrm{~km}$ e $2.540,34 \mathrm{~km}$. Elesbon (2004) encontrou, para a extensão do rio principal e, o comprimento total dos cursos d'água, os valores de $230 \mathrm{~km} \mathrm{e}$ $974 \mathrm{~km}$, respectivamente, trabalhando na escala de 1:1.000.000. Esse resultado evidencia o efeito de se trabalhar com diferentes escalas, principalmente no que se refere ao comprimento total da drenagem, no interior da área da bacia.

A densidade de drenagem encontrada para a região em estudo foi de 0,367 $\mathrm{km} \mathrm{km}^{-2}$. Assim, a referida bacia foi considerada como uma bacia hidrográfica

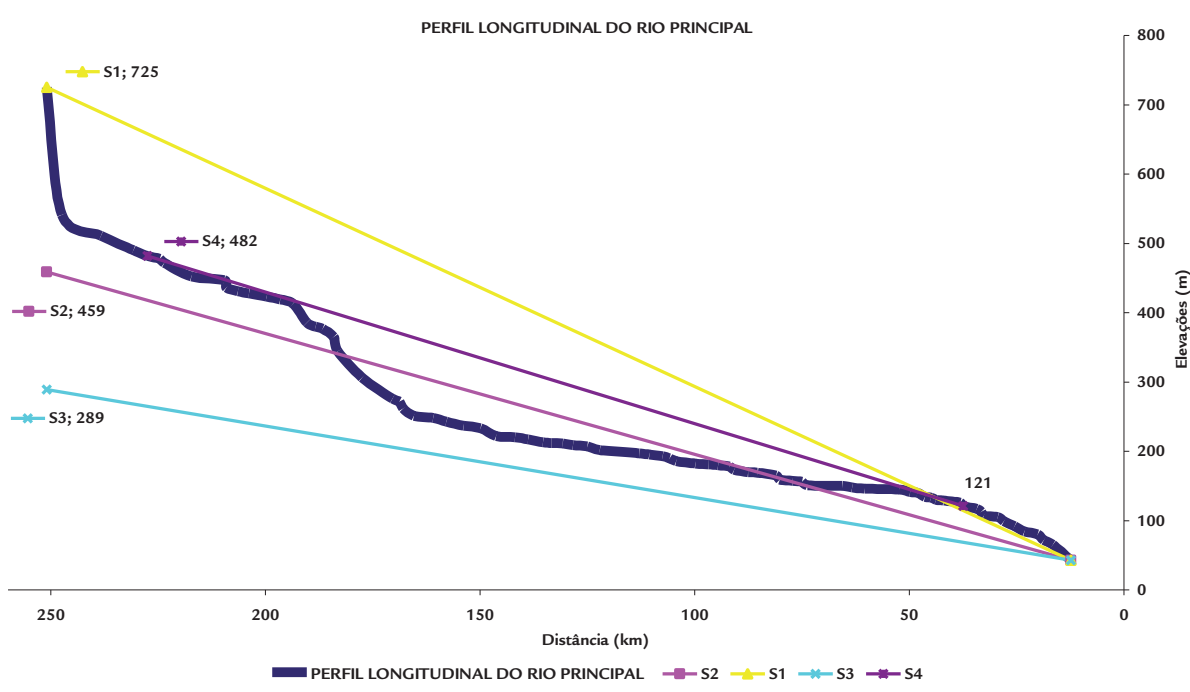

O modelo S3 é aquele que melhor representa a declividade do rio, porque leva em consideração o tempo de percurso da água ao longo da extensão do perfil longitudinal. A declividade estimada pelo modelo S3 foi calculada dividindo-se a extensão

\section{Conclusões e recomendações}

Os Sistemas de Informações Geográficas (SIG's) se mostraram uma ferramenta eficiente no que diz respeito à obtenção das características físicas da bacia, de uma forma simples e automatizada.

A ferramenta auxilia na apresentação dos resultados, sendo fácil a combinação de vários mapas, ganho essencial na reprodutibilidade dos resultados obtidos.

A drenagem numérica gerada a partir do MDEHC, para um acúmulo de do rio em diversos trechos retilíneos, obtendo-se valor de 0,0011 m.m.1. Elesbon (2004) obteve, para a região em estudo, uma declividade média do rio principal de $0,0079 \mathrm{~m} . \mathrm{m}^{-1}$, mais de 7 vezes superior ao valor encontrado nesse trabalho.
500 células mostrou-se representativa em seu grau de ramificação, comparativamente à hidrografia digitalizada a partir da carta topográfica do IBGE na escala 1:250.000.

Sugere-se, para uma padronização na modelagem hidrográfica, que a base de dados oficial forneça, precisamente, a posição geográfica de todas as nascentes das bacias hidrográficas, para uma melhor definição no nível de ramificação das drenagens modeladas.

Foi constatada uma melhoria nos mal drenada segundo Vilella e Matos (1975). Elesbon (2004) encontrou, para a região em estudo, densidade de drenagem de $0,13 \mathrm{~km} \mathrm{~km}^{-2}$. Deve-se ressaltar que todas as características relativas à rede de drenagem são altamente influenciadas pela escala do mapa utilizado no trabalho.

No presente estudo, constatou-se que a rede de drenagem da bacia, ordenada pelo método de Strahler, foi igual a 5 e a densidade de confluências igual a 0,068 confluências. $\mathrm{km}^{-2}$.

A declividade média obtida, nesse trabalho, foi de 21,24\%, que, segundo EMBRAPA (1999), se enquadra em relevos fortemente ondulados.

$\mathrm{Na}$ Figura 4, está apresentado o perfil longitudinal do rio principal com as declividades teóricas S1, S2, S3 ou S4.
Figura 4

Declividades do rio principal (S1, S2, S3 e S4).

A facilidade, a eficiência e a reprodutibilidade dos dados de elevação e drenagem a partir do MDEHC, essenciais para a obtenção de variáveis hidrológicas e ambientais, podem ser consideradas as maiores contribuições desse trabalho. resultados apresentados nesse trabalho em comparação com os resultados obtidos em trabalhos anteriores. Cabe ressaltar que a diferença de escala e o procedimento totalmente automático foram os principais motivos nos desvios dos resultados obtidos.

Recomenda-se a execução de outros trabalhos científicos em relação às variáveis morfométricas utilizadas para a região em estudo, visando a uma melhor compreensão desses valores em diferentes escalas e resoluções. 


\section{Agradecimentos}

Os autores agradecem o apoio financeiro concedido pelo Conselho $\mathrm{Na}$ -

\section{Referências bibliográficas}

cional de Pesquisa (CNPq) e pela Fundação de Amparo à Pesquisa do Estado de
Minas Gerais (FAPEMIG), que viabilizou a realização desse trabalho.

ALCARAZ, S. A. et al. Comparison of methodologies for automatic generation of limits and drainage networks for hidrographic basins. Revista Brasileira de Engenharia Agrícola e Ambiental, v.13, n.14, p.369-375, 2009.

ALVES, J. M. P., CASTRO, P. T. A. Influência de feições geológicas na morfologia da bacia do rio Tanque (MG) baseada no estudo de parâmetros morfométricos e análise de padrões de lineamentos. Revista Brasileira de Geociências, v. 33, n. 2, p. 117-127, 2003.

ANA - AGÊNCIA NACIONAL DE ÁGUAS. Hidroweb - Sistema de Informações Hidrológicas. Disponível em: < http://hidroweb.ana.gov.br/>. Acesso em abril de 2010.

CARDOSO, C. A. et al. Caracterização morfométrica da bacia hidrográfica do rio Debossan, Nova Friburgo, RJ. Revista Árvore, Viçosa-MG, v. 30, n. 2, p. 241-248, 2006.

COLLARES, E, G. Avaliação de alterações em redes de drenagem de microbacias como subsídio ao zoneamento geoambiental de bacias hidrográficas: aplicação na bacia hidrográfica do rio Capivari - SP. São Carlos: Escola de Engenharia de São Carlos, Universidade de São Paulo. 2000, 194f. (Tese de Doutorado).

COLOMBO, R. et al. Deriving river networks and catchments at the European. $\mathrm{Ca}$ tena, v. 70, p. 296-305, 2007.

ELESBON, A. A. A. Utilização de sistemas de informação geográfica na regionalização de vazões-estudo de caso: bacias dos rios Mucuri, Itaúnas e São Mateus. Vitória: Universidade Federal do Espírito Santo, 2004. 129f. (Dissertação de Mestrado).

EMBRAPA - EMPRESA BRASILEIRA DE PESQUISA AGROPECUÁRIA. Centro Nacional de Pesquisa de Solos. Sistema brasileiro de classificação de solos. Rio de Janeiro, 1999. 412p.

ESRI - Environmental Systems Research Institute. Help on line. Disponível em: <http:// resources.esri.com/arcgisdesktop/>. Acesso em abril de 2010.

FREDRICK, K. C. et al. Development of a numerical groundwater flow model using SRTM elevations. Hydrogeology Journal, v.15, p.171-181, 2007.

GARBRECHT, J., MARTZ, L. W. Digital elevation model issues in water resources modeling. ESRI, USERS CONFERENCE, 19., 1999, San Diego. Proceedings... San Diego: 1999. CD-ROM.

LANA, C. E. et al. Análise morfométrica da bacia do rio do Tanque, MG - Brasil. Rem: Revista Escola de Minas, v. 54, n. 2, p. 121-126, 2001.

LIMA NETO, R. T. et al. Análise morfométrica e ambiental da microbacia hidrográfica do rio Granjeiro, Crato/CE. Rem: Revista Escola de Minas, v. 61, n. 3, p. 365-369, 2008.

LIMA, W. P. Princípios de hidrologia florestal para o manejo de bacias hidrográficas. Piracicaba, SP: Escola Superior de Agricultura "Luiz de Queiroz" (ESALQ), 1986. 242p.

LUDWIG, R., SCHNEIDER, P. Validation of digital elevation models from SRTM XSAR for applications in hydrologic modeling. ISPRS Journal of Photogrammetry \& Remote Sensing, v.60, p.339-358, 2006.

MARQUES, F. de A. et al. AQUORA - Sistema multi-usuário para gestão de recursos hídricos. Revista Brasileira de Recursos Hídricos, v. 14, n. 4, Out/Dez, p. 51-69, 2009.

MIRANDA, E. E. de (Coord.). Brasil em Relevo. Campinas: Embrapa Monitoramento por Satélite, 2005. Disponível em: <http://www.relevobr.cnpm.embrapa>. Acesso: 24 set. 2009.

OLIVEIRA, P. T. S. de et al. Caracterização morfométrica de bacias hidrográficas através de dados SRTM. Revista Brasileira de Engenharia Agrícola e Ambiental, v.14, n.8, p.819-825, 2010.

PIRES, J. S. R. et al. A utilização do conceito bacia hidrográfica para a conservação dos recursos naturais. In: SCHIAVETTI, A., CAMARGO, A. F. M. (Ed.). Conceitos de bacias hidrográficas: teorias e aplicações. Ilhéus, BA: Editus, 2002. p. 17-35. 
PRUSKI, F. F. Conservação de solo e água: práticas mecânicas para o controle da erosão hídrica. Viçosa: UFV, 2006. 240 p.

RABUS, B. et al. The Shuttle Radar Topography Mission - a new class of digital elevation models acquired by spaceborne radar. ISPRS Journal of Photogrammetry \& Remote Sensing, v.57, p.241-262, 2003.

RENNÓ, C. D. et al. HAND, a new terrain descriptor using SRTM-DEM: Mapping terra-firme rainforest environments in Amazonia. Remote Sensing of Environment, v.112, p.3469-3481, 2008.

SANTOS, C. A. dos, SOBREIRA, F. G. Análise morfométrica como subsídio ao zoneamento territorial: o caso das bacias do Córrego Carioca, Córrego do Bação e Ribeirão Carioca na região do Alto Rio das Velhas-MG. Rem: Revista Escola de Minas, v. 61, n. 1, p. 77-85, 2008.

SOUZA, C. G. et al. Caracterização e manejo integrado de bacias hidrográficas. Belo Horizonte: EMATER, 2002. 124p.

STRAHLER, A. N. Hypsometric analysis of erosional topography. Bull. Geol. Soc. Am., n. 63, p. 111-1141, 1952.

TUCCI, C. E. M. (Org.). Hidrologia: ciência e aplicação. Porto Alegre: Editora da UFRGS/ABRH, 2004. 943p.

VALERIANO, M. M. et al. Modeling small watersheds in Brazilian Amazônia with SRTM-90m data. Computers \& Geosciences, v.32, n.8, p.1169-1181, 2006.

VILLELA, S. M.; MATTOS, A. Hidrologia aplicada. São Paulo: McGraw-Hill do Brasil, 1975. 245p.

Artigo recebido em 27 de abril de 2010. Aprovado em 25 de abril de 2011. 